Journal of Sustainable Development of Transport and Logistics

journal home page: https://jsdtl.sciview.net

Nazneen, S., Rezapour Mashhadi, R., \& Ksaibati, K. (2020). Implementing safety toolkit on the Fort Peck Indian Reservation, Montana. Journal of Sustainable Development of Transport and Logistics, 5(1), 6-18. doi:10.14254/jsdtl.2020.5-1.1.

\title{
Implementing safety toolkit on the Fort Peck Indian Reservation, Montana
}

\author{
Sahima Nazneen *, Mahdi Rezapour Mashhadi * \\ ${ }^{*}$ Department of Civil \& Architectural Engineering, University of Wyoming, \\ Office: EN 3084, 1000 E University Ave, Dept. 3295, Laramie, WY 82071, USA \\ snazneen@uwyo.edu \\ ${ }^{* *}$ Department of Civil \& Architectural Engineering, University of Wyoming, \\ Office: EN 3084, 1000 E University Ave, Dept. 3295, Laramie, WY 82071, USA \\ mrezapou@uwyo.edu \\ ${ }^{* * *}$ Wyoming Technology Transfer Center, \\ 1000 E. University Avenue, Department 3295, Laramie, WY 82071, USA \\ khaled@uwyo.edu
}

\section{open 2 access co do}

\section{Article history:}

Received: January 18, 2020

1st Revision: February 21, 2020

Accepted: April 06, 2020

\section{DOI:}

10.14254/jsdtl.2020.5-1.1

\begin{abstract}
Indian Reservations have suffered from high crash rates that lead to fatal and incapacitating injuries for years. Among numerous issues, resource gap, rustic nature of the reservations, cross jurisdictional issues, and scarce crash data, act as obstacles in an effort to reduce the number of these fatal and serious crashes. Numerous organizations have recognized the importance of addressing issues on Indian reservations and improving roadway safety. Wyoming Technology Transfer Center / Local Technical Assistance Program (WYT2 2 LTAP) center developed a safety toolkit for tribal communities to ascertain high-risk crash locations and determine the low-cost safety improvement countermeasures. This safety toolkit acts as a guideline providing information, field examples, and resources in key topic areas to improve roadway safety through the use of the five-step methodology from Wyoming Rural Road Safety Program. These steps included compiling and crash data analysis, level I field evaluation, combined ranking, level II field evaluation, and benefit-cost analysis. In this study, the safety toolkit was implemented on the Fort Peck Indian Reservation (FPIR), Montana, to provide the tribes with a real-life example. This study reveals that low- cost safety countermeasures have significant impacts in reducing the number of fatal and serious injury crashes on the FPIR. This methodology with slight modification can be applied to other Indian reservations or similar entities to improve roadway safety.
\end{abstract}

Keywords: Indian reservation, crashes, tribes, crash injury.

Corresponding author: Mahdi Rezapour Mashhadi

E-mail: mrezapou@uwyo.edu 


\section{Introduction}

Roadway safety on Indian reservations has been one of the main concerns in the United States for decades. While the whole nation experiences reduction in fatality per capita, Indian reservations are still struggling with higher fatality rate per capita. According to Fatal Analysis reporting system (FARS), 511 Native Americans / Alaska Natives were killed in motor vehicle crashes in 2013 (Bureau of Indian Afairs , 2016). The high fatal crash rate is attributable to perilous driving behavior, limited crash data, resource gap, and inadequate coordination among different jurisdiction.

As sovereign nations, Indian reservations are unique in many aspects. Non-Uniform traffic safety laws on many reservations make it more challenging to improve roadway safety in these areas. Timely and accessible crash data is another challenge as tribes are not bound to provide crash reports to the state agency. To improve roadway safety on Indian reservations, addressing these challenges and determining factors contributing to the high crash rate are essential.

Numerous studies have been conducted to address the challenges and seek solutions to the high crash rate on Indian reservations. But data collection and analysis practices in these areas as well as the issues stated above hinder efforts to identify high crash risk areas. Wyoming Technology Transfer Center (WYT2 ${ }^{2}$ LTAP) developed a safety toolkit to reduce the elevated crash rate in these areas. The toolkit, based on previously established five-step methodology elaborately describes the procedures for determining contributing factors of the crash and identifying high-risk crash locations. However, the previous study lacked the application of the discussed methodology. Thus, this study is set forward to apply the methodology on real life data.

\section{Background}

About 600 federally recognized Indian Tribes reside in 326 Indian reservation across the United States. Indian Reservations consist of about 145,000 miles of roadway under the jurisdiction of the tribal, federal, state, and local governments (Highways and Highway Safety on Indian Lands, 2016). Motorists travel more than 2 billion vehicle miles (3.2 billion vehicle kilometers) each year on the Indian Reservation Roads (IRR) (Sullivan \& Martin, 2009). These roads has been witnessing higher rate of fatal crashes over the years than the other areas across the United States (Highways and Highway Safety on Indian Lands, 2016). National Center for Statistics and Analysis stated that between the year of 1975 and 2002, the fatal crashes per year in Indian reservations increased by 52.5 percent, while the fatalities involved with crashes in the whole country dropped at a rate of 2.2 percent ( (Poindexter, 2004). Poor road conditions, rural nature of the roadway, dangerous driving behaviors contribute to the elevated rate of fatalities in reservations. Federal Highway Administration (FHWA), the Office of Federal Lands Highway (FLH), and the U.S. Department of the Interior's BIA provide funds for planning, design, and maintenance of these roadways through the Tribal Transportation programs (formally known as the IRR program). Although comprehensive information of most of the Indian reservations roadways is not accessible, data on the BIA-system roads imply that most of the roads are in very miserable condition. In fact, $70 \%$ of the 90,000 miles IRR, maintained by the BIA, are not paved (Highways and Highway Safety on Indian Lands, 2016). According to the BIA reports in 2014, 83\% of the BIA-system road miles were not in acceptable conditions (Highways and Highway Safety on Indian Lands, 2016).

The National Highway Traffic Safety Administration (NHTSA) stated that sixty-five percent (65\%) of the people who died in motor vehicle crashes on Indian reservations were unrestrained at the time of the fatal crashes (Fatality Analysis Reporting System(FARS), (2010-2014)). Further, about 40 percent of deadly crashes on Indian reservations were alcohol-related, where alcohol accounted for 31 percent of total crashes nationally during the same period.

The advancement of transportation systems on tribal lands has become an utmost priority to keep pace with the increasing traffic volume attributable to growing communities. Tribal governments, with the assistance of federal, State, and local government agencies, are struggling with the challenges of building, maintaining and operating safe roadways. Each tribe is unique in ways they operate culturally and ethically, which indicates that a one-size-fits-all approach is not realistic and effective for tribal communities (Sullivan \& Martin, 2009). Currently, numerous organizations have been working to address issues on Indian reservations and improve roadway safety to reduce crashes. 
The FHWA established Tribal Technical Assistance Program (TTAP) in 1991 to assist tribal governments in improving their transportation networks (FHWA, n.d.).

This program provides tribal communities with an array of programs such as training programs, information clearinghouses, updates on new and existing technologies, and personalized technical assistance to improve road safety. Also, the Office of Federal Lands Highway (FLH) has been arranging Tribal Safety Summits with the focus on critical issues to improve transportation safety on tribal lands since 2008 (Tribal Transportation Safety, n.d.). In these summits, tribes across the country express their concerns about inadequate resources or expertise, jurisdictional issues in developing strategic traffic safety plan for their reservations.

WYT $^{2}$ /LTAP center developed the Wyoming Rural Road Safety Program (WRRSP), funded by the Mountain-Plains Consortium (MPC) and Wyoming Department of Transportation (WYDOT) in cooperation with the FHWA, to ascertain high-risk rural locations and develop a strategy to secure funding for reducing crashes on the riskiest areas (Ksaibati, Zhong, \& Evans, 2009) As a derivative of the WRRSP, a low-cost five-step safety improvements program was developed for the tribal communities to improve safety on their roadways. These five steps are, namely, Compilation of crash data and crash data analysis, Level I field evaluation, Combined Ranking, Level II field evaluation, and Benefit-cost analysis. The methodology was first implemented on Wind River Indian reservation (WRIR) in Wyoming to investigate its effectiveness. This study identified gaps in crash data on Indian reservations and provided suggestion to bridge these gaps. To identify appropriate safety improvements, the issue involving the lack of crash data must be resolved (Shinstine \& Ksaibati, 2013). This study also developed statistical models to describe crash severity on the WRIR for several highway systems including interstates, state, and U.S. highways, county local rural roads and Indian Reservation Roads. The model results provided useful information on critical crashes for rural roads within Wyoming and the WRIR (Shinstine, Wulff, \& Ksaibati, 2016) .The models identified five main factors, such as animals, impairment, motorcycles, mean speed, and safety equipment as predominant predictors in four highway systems.

After the successful implementation on the WRIR, the program was expanded on the Standing Rock Sioux Tribe (SRST), Sisseton Wahpeton Oyate (SWO), and Yankton Sioux Tribes (YST). It showed great success in reducing the number of fatal and incapacitating injuries occur in those reservations roadways. Despite the success of the methodology, different challenges and difficulties were faced while implementing the five-step road safety process on these reservation roadways, implying that a single method does not work for all areas. Therefore, a safety toolkit is developed to assist tribes across the country in implementing the methodology, adequately compatible with the unique nature of the area, on site data, preference by the tribes, and other factors to meet the demands. In this study the safety toolkit was implemented on the Fort Peck Indian Reservation to investigate its effectiveness. This study provides the opportunity to test the applicability of the safety toolkit and identify the necessary modification. This method with some modifications can be also used on other areas to evaluate crashes data and improve traffic safety.

\section{Research objective}

The main objective of this research is to implement the safety toolkit on the Fort Peck Indian reservation (FPIR) in Montana. This study provides insight into the challenges and opportunities that exist for FPIR in implementing the safety toolkit.

\section{Fort Peck Indian Reservation}

The Fort Peck Indian Reservation (FPIR) is situated in the northeast corner of Montana, with the Missouri river neighboring its southern perimeter. Two separate Indian nations, the Sioux and the Assiniboine live in the FPIR. The area of this reservation is about 2,093,318 acres (approximately 3,200 square miles). This area consists of about 378,000 acres of tribally owned and 548,000 acres of individually allotted Indian lands. The total of Indian owned land is about 926,000 acres (Fort Peck Assiniboine \& Sioux Tribal History, n.d.)

Like many other tribal governments, the Fort Peck Tribes work with limited resources to manage and maintain their transportation programs and contracts, in association with the Bureau of 
Indian Affairs (BIA). Most of the county roads in this reservation are jointly maintained by FPIR transportation and the County Road and Bridge Department, while some roads are managed solely by FPIR transportation. There are approximately 1,500 miles of roadways in the FPIR which comprise of 375 miles of BIA system and Tribally-owned roads. Of the 211 miles of BIA-owned roads, more than $50 \%$ are gravel and dirt roads (Terrill, Ksaibati, \& Thompson, 2016). Most of the roads are built a long time ago and not maintained properly.

The Fort Peck Tribes are committed to reduce the number of fatal and severe crashes and improve transportation safety. The transportation director of the FPIR has been trying extensively to make collaboration with various government agencies to access funding and resources in enhancing the FPIR roadway safety. Four elements of highway safety- engineering, enforcement, education, and emergency services are required to be addressed to succeed in improving transportation safety on the reservation. (Terrill, Ksaibati, \& Thompson, 2016)

\section{Safety toolkit}

The five-step methodology from the WRRSP is used as a prototype to develop the safety toolkit for Indian reservations. The process can be modified according to the available data, preference by the Tribes, and other factors to meet the needs of the Tribes. This process includes analyzing crash data and developing a systemic approach based on field verifications. The five-step procedure is as follows:

1. Crash data analysis.

2. Level I field evaluation.

3. Combined ranking to identify potential high-risk locations based on steps 1 and 2 .

4. Level II field evaluation to identify countermeasures.

5. Benefit-cost analysis.

\section{Помилка! Неправильне посилання закладки.: Safety Improvement Program Procedure}

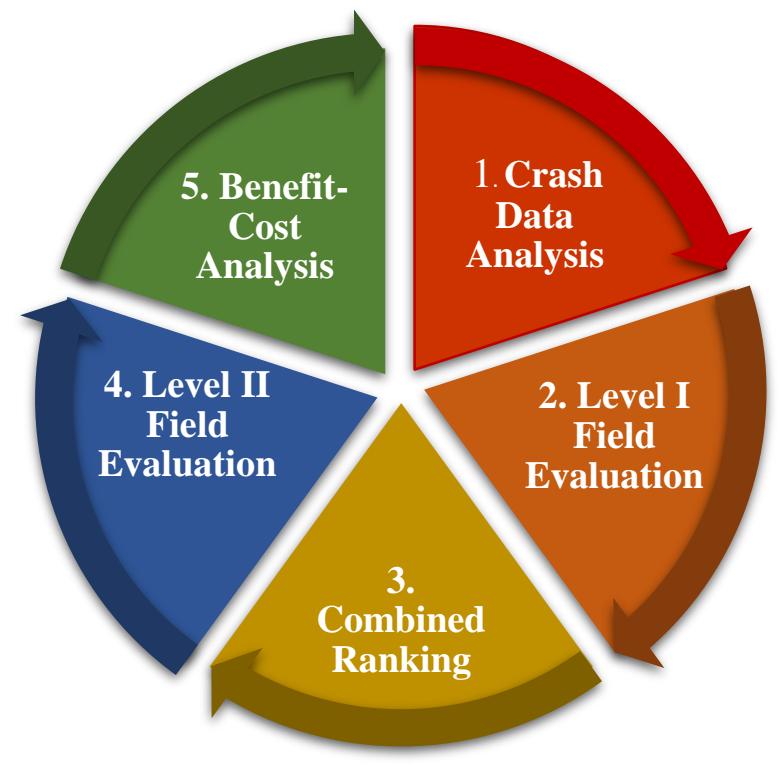

Figure 1 shows the sequence of the steps. The process can be altered according to the needs of the tribes. This section briefly describes the steps of the safety toolkit

The first step in conducting a safety improvement program is to assemble the available data and analyze them. Crash data, traffic volumes and roadway characteristics data, driver behavioral data, anecdotal data are studied to understand the significant factors that contribute to crash occurrence. After compiling and analyzing available crash data, a ranking is established based on the high crash locations. The second step in the safety evaluation, level I field evaluation, is a systematic way to determine the high-risk rural locations and provide a ranking based on roadway conditions. In this step, the roadways are reviewed at one-mile segments, and each segment is rated from 0 to 10 , with 0 being the worst and 10 the best. After that, each segment is provided with a ranking from the lowest 
score to the highest score. Crash ranking and level I ranking are then combined to provide a list of proposed roadways considered for safety improvements. As soon as the Tribes have identified their priority sites, level II evaluation is conducted on each of the routes selected. This step will determine the potential countermeasures to address the safety concerns. Finally, Based on the selected countermeasures and associated costs, benefit-cost analysis is performed for each project. This is calculated as the net present dollar value of benefits and is provided as a cost estimate for the tribes. Construction costs, environmental costs, planning and design costs, and ongoing maintenance costs are estimated for the safety improvements.

The following sections describe the application of each step on the FPIR in detail.

\section{Crash data analysis}

The analysis of crash data is the first step in the roadway safety program methodology. To determine appropriate countermeasures, factors associated with crash must be reviewed, and four E's of safety must be addressed. The crash database was obtained from the Montana Department of Transportation. It covers a ten-year period from 2005 to 2014. During this period, 940 crashes occurred on state, county, city and tribally-owned roads.

In this section, Descriptive statistics is performed to assess the overall condition of the FPIR. Crash injury level is divided into three levels including critical, serious, and property damage only crashes. Critical crashes consist of fatal and incapacitating crashes. Serious crashes include nonincapacitating and possible injuries, and the Property Damage Only (PDO) crashes are the crashes without any injury.

Figure 1 shows a graphical representation of this data. Since unknown severity level made up of only two percent of crash data, it was excluded in crash data analysis. The subsequent sections will provide the percentage distribution of crashes by several factors.

Figure 2: Percentage distribution of crash by severity level

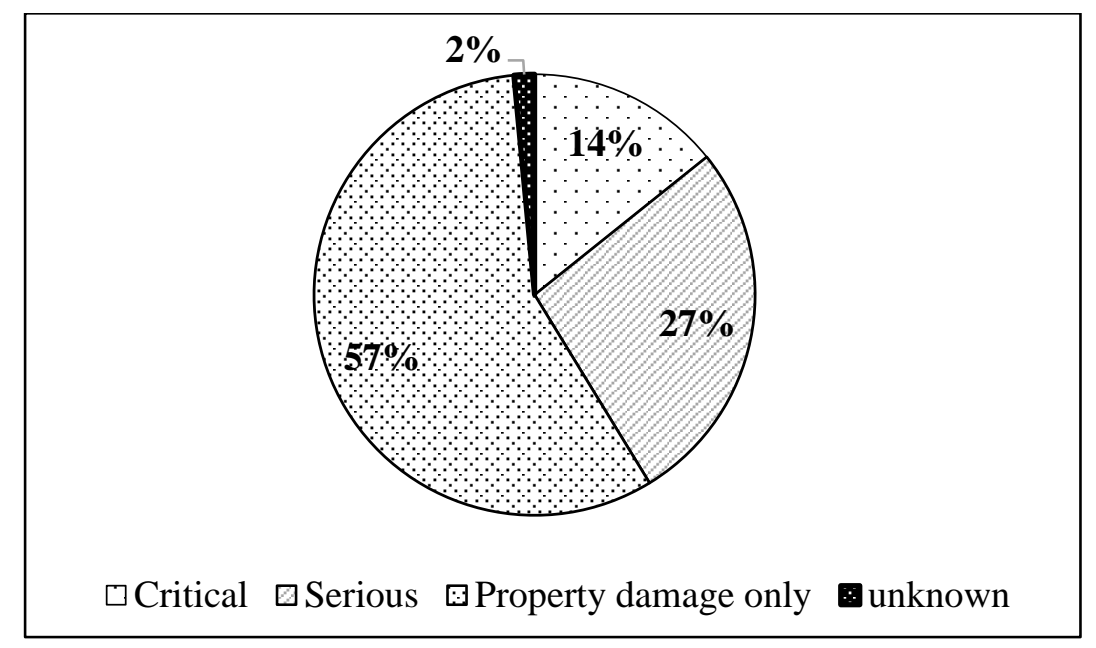

Analyzing the crash severity during different weather conditions can reveal whether or not weather or road surface conditions are playing a significant role in the prevalence and severity of crashes on the FPIR. Distribution of crashes by weather reveals that critical crashes had the highest percentage of crashes occurred in cloudy condition. About $56 \%, 42 \%, 34 \%$, and $31 \%$ of total crashes occurred during fog, blowing snow, cloudy, and snowy weather conditions respectively, which was accounted for serious crashes. Furthermore, during rain and sleet/hail PDO crashes had the highest percentage of the total crashes.

Lighting condition refers to the presence of light at the time of crash occurrence. Crashes by lighting condition depicts what percentage of critical crashes were high during the absence of daylight. During the dark, dawn and dusk, 30\%, 25\%, and 23\% respectively of total crashes were accounted for critical crashes. Also, a high percentage of serious injury crashes were observed during dawn, dark and daylight. This type of crash made up $42 \%, 31 \%$ and $28 \%$ of total crashes occurring at the time of dawn, 
dark, and daylight. Furthermore, PDO crashes had high percentages such as 71\%, 62\%, and 61\% during dark-lighted, dusk, and daylight condition respectively.

In case of First harmful events, critical crashes comprised 53\%, 38\%, 33\% of total crashes involved with the pedestrian, ditch/embankment, and non-collision respectively. Moreover, severe crashes made up $41 \%, 41 \%$, and $35 \%$ of the crashes involved with pedestrian, non-collision, and ditch/embankment respectively. Again, $82 \%$ and $81 \%$ of crashes involved with other FHE and animal respectively were accounted for property damage only crashes. Though the pedestrian-related crashes were only $2 \%$ of the total number of crashes within the FPIR, its higher percentage of critical and severe injuries leads to the concern of pedestrian safety in the reservation. However, motor vehicle crashes held $44 \%$ of all crashes which leads to high percentage of PDO crashes.

Indian reservations have a high prevalence of alcohol-impaired driving and the highest alcoholrelated motor vehicle death rate of all races (Tribal Road Safety : Get the Facts, 2017). Analysis of crashes by whether or not a driver was under the influence of drugs or alcohol at the time of crashes reveals that $24 \%$ of the crashes occurred with a driver under the influence of a substance, and $61 \%$ of the crashes occurred when a driver was considered in the normal state. When the drivers were under the influence of drugs, critical and serious injury made up 38\% and 36\% of crashes respectively. On the other hand, the percentage of PDO crashes is higher when a driver was in a normal state. However, $15 \%$ of the crashes were reported with unknown driving conditions posed a large gap in the crash data.

According to Center for disease control, motor vehicle crashes are the leading cause of death for American Indians aged 1-44 (Center for Disease Control and Prevention, 2014). Crash data of the FPIR portrayed that the FPIR is not an exception. People between 25 and 34 years old had the highest crash rate per 1,000 population followed by 35-44 years old. Drivers aged 44 years and younger were more vulnerable to crashes than the older generations in the FPIR. This correlates with the concern that more crashes are occurring with young drivers on the reservation. Population by age group in FPIR for 2010 is collected from American Census of Bureau and used as an average of 10 years population (American FactFinder, 2010).

Native American males are at high risk of crashes. Compared to their female counterparts, men aged 20 years and older are twice as likely to die from a motor vehicle crash and three times more likely to die from pedestrian-related injuries (Center for Disease Control and Prevention, 2014). Sixty four percent of crashes occurred with male drivers on the FPIR while in the national level, it was about $57 \%$ (NHTSA, 2015). On the other hand, 36\% of the crashes occurred with the female driver on the FPIR compared with the national proportion of $43 \%$.

The usage of seat belts and child safety restraints is one of the leading concerns when it comes to analyzing crashes on tribal lands. $70 \%$ of the tribes who died in motor vehicle crashes were not wearing a seatbelt at the time of the fatal crashes (Herbel \& Kleiner, 2010). In the FPIR, 32\% of the crashes occurred without seatbelt usage while $43 \%$ occurred with seatbelt usage. This huge percentage of not using seatbelt makes the safety restraint usage leading concerns regarding crashes. However, $25 \%$ of the crashes were reported with unknown usage which indicates the large gap in crash data.

\section{Comparative analysis}

In this section, comparative analysis among the roads under three jurisdictions: Indian Tribe nation, City and County highway agency, and state highway agency is performed in determining dominant factors affecting crash injury in these roadways.

Crash severity in this analysis was made up of three categories, critical, serious, and PDO, relative to the KABCO scale. Critical and serious crashes had the highest percentage of roads maintained by the Tribe at $34 \%$ and $38 \%$ respectively. On the other hand, state highways within the reservation experienced critical crashes at $15 \%$ and serious crashes at $29 \%$ of total crashes occurred on these roads. Roads under the jurisdiction of the city or municipal and county highway agency had the highest PDO crashes at 78\% percent and the lowest percentage of critical and serious crashes at $2 \%$ and $17 \%$ respectively. This analysis supports the fact that fatal and serious crashes are much higher on Indian reservation roads. 
The First Harmful Event was broken into six categories: Animal, Motor vehicle, Non-collision, Pedestrian, Fixed object, and other. Indian reservation roads had the highest percentage of noncollision crashes at $40 \%$. Non-collision crashes comprised mostly overturn/rollover-related crashes. Such a high rate of overturning/rollover road crashes could be attributable to poor signage and higher travel speeds on these rural roads. The city or municipal roads and state highways had the highest percentage of motor vehicle crashes at $60 \%$ and $44 \%$ respectively, where motor vehicle crashes made up $44 \%$ of the total number of crashes within the FPIR.

Roads under the jurisdiction of Indian Tribe Nation held the highest percentage of crashes under the influence of drugs or alcohol at 43 percent. The state highways on the reservation had the second highest at 23 percent of the total crashes. Roads under the jurisdiction of the city or municipal highway agency had 16 percent crashes related to impaired driving. Impaired driving is a significant risk and behavioral factor to the safety of the roadways on the reservation. More energy needs to be invested in addressing this issue.

The use of safety restraints has been another leading behavioral factor to crashes on the reservation. When comparing the three systems in the FPIR, the local roadways on the reservation held the highest percentage of crashes for not using safety restraint at $53 \%$. City and county roads had $23 \%$ and $31 \%$ of crashes respectively when safety restraints were not used. These considerable percentages of not using safety restraints naturally lead to safety concerns on the FPIR. Another observation to be noted is the number of crashes where the seatbelt restraint use was unknown.

Driver gender can also be a contributing behavioral factor to crashes. In State highways within the FPIR, $67 \%$ of total crashes had the male drivers where $31 \%$ crashes had the female drivers. $65 \%$ of crashes occurred on Indian reservation roads involved with the male driver and $29 \%$ of crashes involved with the female driver. However, city-county agency maintained roads had 49 percent crashes with the male drivers, and 42 percent crashes with the female drivers.

\section{Crash ranking}

After the crash data analysis, the road segments were sorted by the highest number of crashes per segment. The ranking was started with number one, and hot spots with same scores received an equal rank. However, the next rank number would be that associated with the total number of segments so far ranked. From the initial crash analysis, it was determined that it would be more feasible to evaluate the top roads with the high crash rate. Therefore, top 14 roads maintained by the Indian tribe nation, 15 roads maintained by the city and county highway agency, and 15 roads under the jurisdiction of state highway, were selected based on crash rates per mile. Table 1 presents crash ranking for the three types of the roadway system.

\begin{tabular}{|c|c|c|c|c|c|}
\hline \multicolumn{2}{|c|}{ IRR } & \multicolumn{2}{|c|}{ City \& County roads } & \multicolumn{2}{|c|}{ State Highways } \\
\hline Road Name & Crash Rank & Road Name & Crash Rank & Road Name & Crash Rank \\
\hline 6th Ave N & 1 & 3rd Ave S & 1 & 1st Ave $S$ & 1 \\
\hline Road 2065 & 2 & 2nd Ave S & 2 & E Main St & 2 \\
\hline BIA route 168 & 3 & 4th Ave $\mathrm{N}$ & 3 & Anaconda St & 3 \\
\hline Road 1053 & 4 & 4th Ave S & 4 & Main St & 4 \\
\hline Jackson $1 \mathrm{Rd}$ & 5 & Custer St & 5 & 3rd Ave N & 5 \\
\hline Frazer Rd S & 6 & 6th Ave S & 6 & 4th Ave N & 6 \\
\hline BIA Route 1 & 7 & E Johnson St & 7 & 3rd Ave S & 7 \\
\hline Wiota Rd & 8 & 6th Ave N & 8 & Us Highway 2 & 8 \\
\hline BIA Route 14 & 9 & 5th Ave S & 9 & Highway 25 & 9 \\
\hline Road 1074 & 10 & Dawson St & 10 & Highway 480 & 10 \\
\hline WSTRE Rd & 11 & Front St & 11 & Highway 13 & 11 \\
\hline Road 1072 & 12 & 5th Ave N & 12 & Highway $250 \mathrm{~W}$ & 12 \\
\hline Three Corners Rd & 13 & Blaine St & 13 & MT Highway 13 & 13 \\
\hline Oswego Rd N & 14 & Eureka St & 14 & Highway $344 \mathrm{~N}$ & 14 \\
\hline & & 1st Ave S & 15 & & \\
\hline
\end{tabular}




\section{Level I field evaluation}

In Level I field evaluation, the top roads from the crash ranking were evaluated based on five categories: General, Intersections and Rail Road Crossings, Signage and Pavement Markings, Fixed Object and Clear Zone, and Shoulder and Right-of-Way. The evaluating team made up of two individuals. Both members were from WYT ${ }^{2} /$ LTAP. Each category was evaluated separately for each one-mile segment assigning a score of 0 to 10 . Zero (0) would be the most miserable condition while ten (10) would be the best. At the beginning of the evaluations, all segments were provided with a rating of five (5) as the average. The members of the field review team evaluated each roadway separately and combined and averaged the scores. For each segment, the final score was attained by summing up scores assigned to all five categories.

After evaluating all roadways, and the segment scores had been tabulated, every segment was combined and sorted from the lowest to the highest score. The ranking was assigned from the lowest to the highest score starting from one. When two scores were same, they received the same rank. Similar to crash ranking, the following rank value would correspond to the line number. The segment with the lowest risk had the highest rank.

Three Corners road and WestRE road were in the initial list of 14 roadways maintained by the Tribe but were excluded from the list due to their locations relative to other roadways. Tribal transportation officials decided that they were not needed to be included in the evaluation. (Terrill, Ksaibati, \& Thompson, 2016)

Due to resource constraints, roads, under the jurisdiction of city and county highway agency and state highway agency, were evaluated through the help of the Google map and Google street view apps. Top 10 city and county roads, with high crash rate, were selected to be evaluated for assessing roadway condition. On the other hand, seven roadways maintained by the state highway agency were selected for evaluation. Under this jurisdiction, $3^{\text {rd }}$ Ave South, $3^{\text {rd }}$ Ave North, and 4th Ave North roads were not evaluated as they had similar characteristics as the county roads. Table 2 presents the road name and their corresponding level I ranking for three roadway systems.

\begin{tabular}{lclclc}
\multicolumn{2}{l}{ Table 2: Level I Ranking on three roadway systems } \\
\hline & \multicolumn{2}{c}{ IRR } & \multicolumn{2}{c}{ City \& County roads } & \multicolumn{2}{c}{ State Highways } \\
\hline Road & $\begin{array}{c}\text { Level I } \\
\text { Ranking }\end{array}$ & Road & $\begin{array}{c}\text { Level I } \\
\text { Ranking }\end{array}$ & Road & $\begin{array}{c}\text { Level I } \\
\text { Ranking }\end{array}$ \\
\hline Road 2065 & 1 & 6th Ave S & 1 & 1st Ave South & 1 \\
Road 1053 & 2 & 3rd Ave S & 2 & Anaconda Street & 1 \\
Frazer Road N & 3 & 2nd Ave S & 3 & East Main Street & 1 \\
6th Avenue N & 4 & 4th Ave N & 4 & Main Street & 4 \\
BIA 168 & 5 & 4th Ave S & 5 & US Highway 2 & Highway 13 \\
BIA Route 1 & 6 & Custer St & 6 & Highway 25 & 6 \\
Wiota Road & 7 & E Johnson St & 7 & & 7 \\
Jackson1 Road & 8 & 6th Ave N & 8 & & \\
BIA Route 14 & 9 & 5th Ave S & 9 & & \\
Road 1072 & 10 & Dawson St & 10 & & \\
Oswego Road & 11 & & & & \\
Road 1074 & 12 & & & & \\
\hline
\end{tabular}

\section{Combined ranking}

The third step in the safety evaluation process was to combine the crash rankings with the Level I rankings. The roads had been sorted by the highest crash rate and the lowest level I score. Two rankings were then tabulated and combined to develop a final ranking for the level II field evaluation. After the ranks were tabulated, the segments were again sorted from the lowest to the highest. The segments with the lowest numbers were considered the most dangerous. Table 3 presents the top roads from the combined ranking in three roadway systems. 


\begin{tabular}{lclccc}
\multicolumn{2}{l}{ Table 3: Combined ranking on three roadway systems } \\
IRR & \multicolumn{2}{c}{ City \& County roads } & \multicolumn{2}{c}{ State Highways } \\
\hline Road Name & Combined Ranking & Road name & $\begin{array}{c}\text { Combined } \\
\text { Ranking }\end{array}$ & Road name & $\begin{array}{c}\text { Combined } \\
\text { Ranking }\end{array}$ \\
\hline Road 2065 & 3 & 3rd Ave S & 3 & 1st Ave S & 2 \\
6th Ave N & 4 & 2nd Ave S & 5 & E Main St & 3 \\
Road 1053 & 6 & 4th Ave N & 7 & Anaconda St & 4 \\
BIA Route 168 & 7 & 6th Ave S & 7 & Main St & 8 \\
BIA Route 1 & 12 & 4th Ave S & 9 & Us Highway 2 & 13 \\
Jackson 1 Rd & 12 & Custer St & 11 & Highway 13 & 17 \\
Wiota Rd & 14 & E Johnson St & 14 & Highway 25 & 16 \\
BIA Route 14 & 17 & 6th Ave N & 16 & & \\
Frazer Rd S & 17 & Dawson St & 20 & & \\
Road 1072 & 21 & 5th Ave N & 21 & & \\
Road 1074 & 22 & & & & \\
Oswego Rd n & 24 & & & & \\
\hline
\end{tabular}

\section{Level II field evaluation}

For the roads, maintained by the Tribes, level I and level II field evaluations were performed concurrently to optimize resources. The field evaluation team discussed countermeasures during level I evaluation, with the understanding that further investigation may be required. Roadway geometrics and other conditions were used to identify countermeasures (Terrill, Ksaibati, \& Thompson, 2016). For city and county roads and state highways within the reservation, level II field evaluation was conducted through the use of the Google map and Google street view.

A list of countermeasures was developed for typical applications on rural roadways, and crash reduction factors were assigned. Information on proven safety countermeasures and crash reduction factors was collected from the FHWA Safety website (FHWA, 2008).

Roads within the reservation were in good condition. Few low-cost countermeasures were required to address the safety issues. Chevrons were suggested on sharp horizontal curves where there was a high prevalence of run off the road crashes. Others countermeasures such as widening of shoulders and adding rumble strips were also recommended for locations with a high incidence of rollover crashes. In most of the residential roads, maintained by city and county agency, with a high presence of intersection-related crashes, advance warning signs need to be updated or added. Pavement marking was also recommended on the roadways where pavement making was faded or absent. Occasionally more enforcement was suggested in areas closer to residential areas.

\section{Benefit-cost analysis}

Once the countermeasures were identified, WYT2/LTAP continued with the benefit-cost analysis. The recommended countermeasures were matched with the countermeasures provided by the FHWA in their Desktop Reference for Crash Reduction Factors (FHWA, 2008). After that, Crash Reduction Factors (CRFs) for each type of treatments were assigned from the FHWA low cost safety countermeasures list.

Cost estimates of the countermeasures was calculated based on MDT 2016 bid tabulations (Eq. 1). Since the crash analysis was performed for a 10-year period, if the service life of a countermeasure was different than 10 years, it was converted to a 10 -year cost. For example, if a countermeasure had a service life of 5 years, the current construction cost would be two times the cost of one application. The total cost was calculated for each road and compared to an overall benefit in the crash reduction for the entire roadway.

$$
\text { Cost }=\frac{10 \text { years }}{\text { Service Life }} \times \text { Present Cost }
$$

The benefit was calculated based on societal crash costs representing the "cost savings" of crashes reduced. Crash cost provided in the HSM, 2009 were initially used in this study.

These crash costs were converted to present cost using inflation rate. In this study, average inflation rate of $1.75 \%$ during the period 2010-2016 (Statista, n.d.) was used to calculate the crash costs for 2016. Also, FHWA countermeasures list provides CRF for Fatal, Injury and PDO crash but 
HSM categorized injury into three severity level (disable injury, evident injury, and possible injury). To account this severity level into the FHWA list, an average injury crash cost was calculated based on the percentage distribution of crash injury for benefit-cost analysis.

The benefit was expressed as the sum of the number of each crash type that is recorded for that roadway multiplied by its respective societal crash cost and CRF.

$$
\begin{gathered}
\text { Anticipated Benefits }=\text { Expected } P D O \text { crashes }{ }^{*} C R F_{P D O}{ }^{*} C_{\text {Crash }} \text { Cost }_{P D O}+\text { Expected Injury } \\
\text { Crashes }{ }^{*} C R F_{\text {Injury }}{ }^{*} \text { Crash Cost } \text { Injury }+ \text { Expected Fatal crashes } \\
{ }^{*} \text { CRF Fatal }+ \text { Crash Cost Fatal }
\end{gathered}
$$

Where: $C R F P D O$ is the crash reduction factor in reducing PDO crashes.

$C R F$ Injury is the crash reduction factor in reducing Injury crashes.

CRF Fatal is the crash reduction factor of reducing fatal crashes.

$$
\text { Benefit Cost Ratio }(\mathrm{BCR})=\text { Present value of benefits } / \text { Present value of costs }
$$

The BCR less than 1.0 means that cost of the countermeasures outweighs the benefit. Among the roads under the jurisdiction of the Indian Tribes, only Oswego road N had the BCR less than 1. Other roads had a ratio ranging from 2.30 to as high as 72.70 . Roads maintained by city and county highway agency had BCR from 3.46 to 44.76 . For roads maintained by the state highway agency, the BCR varies

\begin{tabular}{|c|c|c|c|c|c|}
\hline \multicolumn{2}{|l|}{ IRR } & \multicolumn{2}{|l|}{ City \& County roads } & \multicolumn{2}{|l|}{ State Highway } \\
\hline Road & BCR & Road & BCR & Road & BCR \\
\hline Road 1053 & 72.70 & East Johnson Street & 44.76 & Highway 2 & 278.60 \\
\hline BIA Route 14 & 36.83 & 6th Ave S & 16.50 & Highway 13 & 82.89 \\
\hline BIA Route 1 & 29.39 & 3rd Ave S & 12.26 & 1st Ave S & 21.39 \\
\hline Road 1074 & 12.91 & Dawson Street & 11.78 & Main Street & 13.56 \\
\hline Road 1072 & 12.53 & 2nd Ave S & 9.34 & Anaconda Street & 11.33 \\
\hline Frazer road S & 6.14 & 5th Ave $S$ & 8.18 & Highway 25 & 9.72 \\
\hline 6th Ave N & 5.77 & 4th Ave S & 7.65 & E main St & 6.48 \\
\hline BIA Route 168 & 4.53 & 4th Ave N & 3.60 & & \\
\hline Jackson 1 road & 3.56 & Custer Street & 3.46 & & \\
\hline Road 2065 & 2.30 & & & & \\
\hline Oswego road $\mathrm{N}$ & 0.29 & & & & \\
\hline
\end{tabular}
from 6.48 to 278.60. A closer look at the roads with higher ratios reveals that many of the improvements were pretty low cost, but the benefit of the lives saved and injuries prevented was extremely significant. Table 4 presents the Benefit Cost Ratio of the roads under three jurisdictions.

\section{Conclusions and recommendations}

Native Americans have been struggling with the highest rate of fatal and serious injury crashes among any other ethnicity across the United States. Extreme topography, speeding, impaired driving, and longer response time for emergency vehicles make rural reservation roads more vulnerable to higher fatality rates.

The objective of this study was to implement the safety toolkit on the FPIR to ascertain highrisk crash locations and determine low-cost safety improvements. The safety toolkit provides a fivestep methodology to serve the tribes with the opportunity to identify low-cost safety improvements and distribute funding for these improvements. Successful implementation of the toolkit on the FPIR and other reservations (Shinstine \& Ksaibati, 2013) reflects the adaptability of the five-step process in different Indian reservation areas. Strong cooperation and collaboration among the various stakeholders and tribal members accelerated the success of the program on the FPIR. The high benefitcost ratio of the countermeasures implemented in the FPIR, indicated that small improvements on these rural roads could have a significant impact on the number of fatal and severe injury crashes, proving the effectiveness of the low-cost countermeasures. An excerpt of substantial findings revealed from the analysis is given below: 
- Serious and critical crashes were more likely occurred during adverse weather condition such as cloudy, foggy, and blowing snow.

- Percentage of critical and serious crashes were high during the absence of light such as dark, down, and dusk.

- Pedestrian-related crashes accounted for only $2 \%$ of total crashes within the FPIR, but its higher percentage of critical (53\%) and serious injuries (41\%) leads to the concern of pedestrian safety in the reservation.

- There was also a high prevalence of critical and serious crashes related to collision with ditch/embankment in the reservation.

- The critical and serious injury made up the highest percentage of crashes occurring in nonjunction.

- $24 \%$ of the crashes occurred with the driver under the influence while $61 \%$ of the crashes happened without any influence. However, $15 \%$ crashes with unknown condition pose a gap in the crash data.

- Young drivers were at high risk of crash on the reservation. Age group of 25-34 had the highest crash rate per 1,000 population.

- $32 \%$ of the total crashes, related to without seatbelts makes the safety restraint usage leading concern regarding crashes.

- Roads maintained by the Tribe had the highest percentage of non-collision crashes including rollover crashes, whereas the roads managed by city and county highway agency held the highest percentage of motor vehicle crashes at 60 percent.

- The IRR roadways on the FPIR have a much higher percentage of crashes (43\%) involving drugs and alcohol than on the city and county (16\%) and state highway system (23\%).

- The reluctance of using seatbelt was found more prevalent on the roads maintained by the Tribes.

- The state and U.S. highways were found to be in better condition on the FPIR than the roads under the Tribe and city and county agency.

- BCR ranged from 0.29 to 72.70 for roads maintained by the Tribe, 3.46 to 44.76 for roads under city and county highway agency, and 6.48 to 278.60 for roads maintained by the state highway agency.

- Many inexpensive proposed safety measures listed in the BCR have a considerable impact on the number of fatal and serious injury crashes.

Historically, Indian reservations suffer from incomplete and non-existent crash data. Crash reporting is considered to be an essential issue to address in any safety reviews and strategic plan development and updates. The State DOTs, BIA, TTAPs, LTAPs, and Tribal leadership should put more efforts into resolving the problems that impede good crash reporting. The individuals and organizations who are responsible for maintaining and reporting crash data should focus on determining areas where improvements are required.

The FPIR is suggested to evaluate their roadways system through this methodology to determine other high-risk crash locations and request funding for improvements, either annually or bi-annually. When the countermeasures for the roads are selected and reviewed by the Tribes, the report should be submitted to the MDT to be reviewed for funding. Again, FPIR Strategic Highway Safety Plan should be developed and implemented by the Tribal Safety Council. The WYT2/LTAP can provide necessary assistance to the Tribes to guarantee the success of their safety program. Annual stakeholder meetings are recommended to make the community aware and engaged in the improvement of the roadway safety on the FPIR.

This methodology implemented in this study for the FPIR can be utilized as a template for Indian Nations across the country. As each state and Tribe relationship is unique, altering the program based on specific need, culture, and trend may be required. Coordination, communication, and cooperation among the different authorities are also equally essential to implement the program successfully. Technical support is accessible to all Tribes through the TTAP centers and other government agencies. 


\section{Citation information}

Nazneen, S., Rezapour Mashhadi, R., \& Ksaibati, K. (2020). Implementing safety toolkit on the Fort Peck Indian Reservation, Montana. Journal of Sustainable Development of Transport and Logistics, 5(1), 6-18. doi:10.14254/jsdtl.2020.5-1.1.

\section{References}

American Fact Finder. (2010). Retrieved from American Fact Finder: https://factfinder.census.gov/faces/nav/jsf/pages/index.xhtml

Bureau of Indian Affairs. (2016). 2017 Indian Nations Highway Safety Plan.

Center for Disease Control and Prevention. (2014, October 30). Tribal Road Safety: Get the Facts. (NCIPC) Retrieved 2015, from Injury Prevention \& Control: Motor Vehicle Safety: http://www.cdc.gov/Motorvehiclesafety/native/factsheet.html

Fatality Analysis Reporting System (FARS) (2010-2014). (n.d.). Retrieved from Department of Transportation, National Highway Traffic Safety Administration: https://wwwfars.nhtsa.dot.gov/People/PeopleOccupants.aspx

Federal Highway Administration. (2016, December 20). Transportation Serving Federal and Tribal Lands- 2015 Conditions and Performance. Retrieved from Federal Highway Administration: https://www.fhwa.dot.gov/policy/2015cpr/chap12.cfm

FHWA. (n.d.). Retrieved from Federal Highway Administration: https://www.fhwa.dot.gov/innovativeprograms/centers/local_aid/ttap/

FHWA. (2008). Desktop Reference for Crash Reduction Factors. Retrieved July 2015, from FHWA Safety Program: http://safety.fhwa.dot.gov/tools/crf/resources/fhwasa08011/

Herbel, S., \& Kleiner, B. (June 2010). National Tribal transportation safety summit report. Washington, DC: Department of Transportation, FHWA,.

Highways and Highway Safety on Indian Lands. (2016, February 02). Retrieved from Every CRSReport.com: https://www.everycrsreport.com/reports/R44359.html\#Content

Ksaibati, K., Zhong, C., \& Evans, B. (2009). WRRSP: Wyoming Rural Road Safety Program. Retrieved 2016.

Poindexter, K. (2004). Fatal Motor Vehicle Crashes on Indian Reservations 1975 - 2002. National Center for Statistics and Analysis.

Shinstine, D. S., \& Ksaibati, K. (2013). Indian Reservation Safety Improvement Program A Methodology and Case Study. University of Wyoming, Wyoming Technology Transfer Center. Washington, D.C.: Transportation Research Board.

Shinstine, D., Wulff, S., \& Ksaibati, K. (2016). Factors Associated with Crash Severity on Rural Roadways in Wyoming. Unversity of Wyoming, Department of Statistics. Laramie: Unversity of Wyoming.

Statista. (n.d.). Retrieved from https://www.statista.com/statistics/244983/projected-inflation-ratein-the-united-states/

Sullivan, J., \& Martin, C. (2009). Public Roads. (FHWA) Retrieved 2016, from The Role of TTAPs in Tribal Transportation: http://www.fhwa.dot.gov/publications/publicroads/09novdec/03.cfm

Terrill, T., Ksaibati, K., \& Thompson, C. (2016). Fort Peck Reservation Roadway Safety Improvement Program.

Tribal Road Safety: Get the Facts. (2017). Retrieved from Center for Disease Control and Prevention: https://www.cdc.gov/motorvehiclesafety/native/factsheet.html

Tribal Safety Plans. (n.d.). Retrieved from Office of Federal Lands Highway: https://flh.fhwa.dot.gov/programs/ttp/safety/plans.htm 
Tribal Transportation Safety. (n.d.). Retrieved from http://www.tribalsafety.org/NewsEvents/Summits

Wyoming Highway Safety Management System Committee. (2012). Wyoming Strategic Highway Safety Plan. WYDOT, Cheyenne.

() 2016-2020, Journal of Sustainable Development of Transport and Logistics. All rights reserved. This open access article is distributed under a Creative Commons Attribution (CC-BY) 4.0 license.

Journal of Sustainable Development of Transport and Logistics (ISSN: 2520-2979) is published by Scientific Publishing House "CSR", Poland, EU and Scientific Publishing House "SciView", Poland, EU

Publishing with JSDTL ensures:

- Immediate, universal access to your article on publication

- Immediate, universal access to your article on pub

- High visibility and discoverability via the JSDTL website
- Rapid publication

- Guaranteed legacy preservation of your article

- Discounts and waivers for authors in developing regions 